\title{
Aproximaciones a la población de Panamá Viejo a partir de la arqueología funeraria y la documentación histórica, 1519-1671*
}

\section{Approaching Panamá Viejo's Population Through Funerary Archaeology and Historical Documentation, 1519-1671}

\author{
Bethany Aram. ORCID iD: https://orcid.org/0000-0003-1724-0812 \\ Universidad Pablo de Olavide, Sevilla, España
}

Juan Guillermo Martín. ORCID iD: https://orcid.org/0000-0002-8791-5793

Universidad del Norte, Barranquilla, Colombia / Estación Científica Coiba AIP, Panamá

Iosvany Hernández Mora. ORCID iD: https://orcid.org/0000-0002-7199-8301

Universidad del Norte, Barranquilla, Colombia / Universidad Pablo de Olavide, Sevilla, España

Este artículo contrasta los resultados de distintas campañas arqueológicas en Panamá Viejo con los datos registrados en la documentación histórica, preservada fundamentalmente en el Archivo General de Indias. Analiza registros complementarios que permiten profundizar en la problemática de la conservación parcial de distintos tipos de fuentes, así como sus posibilidades y limitaciones. El consiguiente diálogo interdisciplinar elucida algunas de las trasformaciones que atravesó la población de la zona con la incorporación de indígenas y africanos de diversos orígenes.

PAlabras ClaVE: Arqueología Histórica; Panamá Viejo; Primera Globalización; Población.

This article contrasts the results of excavation campaigns in Panamá Viejo with data registered in historical documentation preserved mainly in the General Archive of the Indies. These complementary collections of material artefacts make it possible to explore problems resulting from the partial conservation of different types of sources and their limitations. The ensuing interdisciplinary exchange elucidates specific transformations that influenced the area's population with the incorporation of indigenous Americans and Africans from different regions.

KeYwords: Historical Archaeology; Panamá Viejo; Early Globalization; Population.

Copyright: (C) 2020 CSIC. Este es un artículo de acceso abierto distribuido bajo los términos de la licencia de uso y distribución Creative Commons Reconocimiento 4.0 Internacional (CC BY 4.0).

* Este trabajo forma parte del ERC CoG 643565, «ArtEmpire», financiado por el European Research Council en el marco del programa Horizonte 2020 y realizado con la colaboración del Patronato Panamá Viejo. 
Una creciente movilidad de personas y bienes de procedencia cada vez más diversa caracteriza el proceso de la primera globalización en un nodo poblacional estratégico como Panamá Viejo, la primera ciudad española fundada en la costa del Pacífico Americano. ${ }^{1}$ Pese a la importancia histórica del asentamiento, no se conservan fuentes documentales locales (municipales, eclesiásticas o de protocolos) pertenecientes a la misma entre 1519 y 1671, salvo en otras colecciones, mayormente del Archivo General de Indias, el Archivo Nacional de Lima, Perú, el Archivo Arzobispal en Lima, la Biblioteca Nacional de España, o la Real Academia de Historia en Madrid. ${ }^{2}$ Esta circunstancia normalmente se achaca a la quema y destrucción de la ciudad en el asedio liderado por Henry Morgan en 1671 y su traslado posterior. ${ }^{3}$ Adicionalmente, las condiciones ambientales de la zona (clima tropical húmedo) llegarían a influir en la conservación tanto de las fuentes históricas como de los restos arqueológicos pertenecientes a esta ocupación.

En una relación conservada en la Biblioteca Nacional de España, el maestrescuela y arcediano de la Catedral de Panamá hizo referencia a los libros de bautismo y registros de enterramientos que custodiaba, hoy desaparecidos, y no únicamente por culpa de Morgan. Según Requejo, los libros referentes a 1561-1603 se habían mojado en las lluvias torrenciales que llegaron a penetrar entre las tejas de la Catedral. Al percatarse de la situación, en un día de sol, los curas y capitulares los sacaron a la Plaza Mayor para secarse, donde fueron comidos por las cabras que allí pastaban. ${ }^{4}$ Por otra parte, los restos de las personas fallecidas no siempre recibían una atención esmerada. Según algunos testimonios, unos 400 difuntos fueron entregados a la orilla del mar durante seis meses de cesación a divinis decretado por el obispo en $1550 .^{5}$ Sin duda, una variedad de sucesos pudo influir en la pérdida o conservación de los registros.

La naturaleza perecedera de muchas fuentes documentales, así como su poca representatividad respecto a la mayoría de la población, otorgan

1 Hernández, Martín y Aram, 2020. La cuestión de la «primera globalización» se desarrolla desde una perspectiva interdisciplinar en la presentación del presente dosier y desde la historia en García Montón y Aram, 2019.

2 Las fuentes conservadas en los repositorios públicos españoles son conocidas por los trabajos de Castillero Calvo, 2006 y 2019; Mena García, 1984 y 1992; y Ward, 1989, 1993, entre otros.

3 Exquemelin, 1967 [1678].

4 «Relación sobre Panamá de D. Juan Requejo y Salcedo», Panamá, 13 de diciembre de 1640, Biblioteca Nacional de España, Madrid (BN), ms. 19245, f. 7v., en Serrano y Sanz, 1908, 20-21.

5 «Visita al obispo Torres», Panamá, 1551, Archivo General de Indias, Sevilla (AGI), Justicia, 393. 
un valor adicional a otros tipos de restos materiales. En este sentido, el abandono de Panamá Viejo en 1671, su protección legal a partir de $1976^{6}$ y su gestión institucional por parte del Patronato Panamá Viejo desde 1995, ${ }^{7}$ han propiciado la conservación e investigación de una parte significativa de la población colonial y prehispánica que se encuentra bajo la superficie de las ruinas de la antigua ciudad. La arqueología histórica, y especialmente la funeraria, abre nuevas perspectivas respecto a los testamentos y registros de bienes de difuntos conservados en la sección de Contratación del Archivo General de Indias. Esta yuxtaposición de fuentes aporta mayor precisión temporal a los contextos arqueológicos y una renovada conciencia espacial respecto a la documentación histórica.

Procuramos no solamente llevar los documentos al campo —como permite la tecnología actual—, sino también valorar la evidencia en el sitio tal y como emerge cara a la interpretación del legado documental durante las excavaciones arqueológicas. Como resultado, no menos dramático por previsible, la realidad arqueológica termina por encausar la interpretación de la evidencia textual y viceversa en distintas escalas. ${ }^{8}$ Concretamente, nuestro acercamiento interdisciplinar buscaba posibles rasgos de una presencia o influencia aborigen en la población colonial de Panamá Viejo, como se había explorado en Chorro de Maíta. ${ }^{9}$ Además, preguntaba si, inicialmente o en algún momento a lo largo de dos siglos, esta misma población colonial enterraba juntos a individuos de distintos y muy lejanos orígenes geográficos, como los procedentes de Campeche. ${ }^{10}$ Aunque la proximidad de sus fosas de inhumación no indica que los mismos individuos vivieran juntos necesariamente, la evidencia tanto histórica como arqueológica apunta hacia la Catedral como un espacio de interacción social. ${ }^{11}$

El diálogo interdisciplinar ha permitido profundizar en el conocimiento de distintas etapas temporales de la población de Panamá Viejo en

\footnotetext{
6 «Ley por la cual se regulan los conjuntos monumentales...», Gaceta Oficial, República de Panamá, 12 de enero de 1977, n. ${ }^{\circ}$ 18252, ley XCI de 22 de diciembre de 1976.

7 Martín y Arango, 2013.

8 Como punto de partida para estas reflexiones, véase Andrén, 1998. Véase también la metodología empleada en Ramos, 2010.

9 Valcárcel Rojas, 2016.

10 Tiesler et al., 2010.

11 Para una noción sociológica normativa de integración social que designa los procesos de incorporación social de diferentes grupos étnicos y su interdependencia a partir de relaciones e interacciones totalmente asimétricas, resultando posiciones diferenciadas en la totalidad social, véase Giner, Lamo de Espinosa y Torres, 2001, 384-385. Y, desde el enfoque de la teoría del intercambio social, véase a Brandon Tuma, 2000 [1992], 2669-2676.
} 
relación con su iglesia mayor o Catedral. Se han logrado distinguir contextos arqueológicos e históricos representativos de un primer periodo que cubre el asiento inicial de la iglesia y Catedral (1519-1541), seguido por otra etapa de reubicación y continua remodelación (1542-1626), que culminó en un uso aún más intenso del espacio mortuorio (1627-1671). Igualmente, el cruce de datos arqueológicos e históricos ha permitido interpretar la diferenciación entre enterramientos en el interior y el exterior del templo. En cada contexto se relacionan los resultados de las excavaciones arqueológicas —unos 151 individuos de época colonial excavados en 2017 en la nave y ocho en el atrio o cementerio, y 14 en el asiento inicial de la iglesia, al sureste de la Plaza Mayor, en las tareas de campo de 2018 (Figura 1), conjuntamente con el material cultural asociado - en relación con la documentación histórica, fundamentalmente los registros de bienes de difuntos provenientes de Panamá, conservados en el Archivo General de Indias. ${ }^{12}$ Se trata, sobre todo, de un encuentro con las evidencias de una población altamente móvil y continuamente renovada.

\section{Una zona de contacto (1519-1541) en el largo plazo}

Un enfoque de los primeros siglos de contacto entre poblaciones americanas, africanas y europeas, y sus procesos de mestizaje en Panamá Viejo tanto culturales como biológicos, no puede dejar de interesarse por los primeros habitantes del sitio arqueológico, normalmente asociados con la lengua franca Cueva y, arqueológicamente, con las regiones denominadas como Gran Darién y Gran Coclé. ${ }^{13}$ Sin embargo, las comparaciones entre las poblaciones pre y post-contacto en relación con la densidad demográfica, longevidad, dieta y salud resultan asimétricas en muchos niveles. Frente a mil años de ocupación prehispánica, Panamá Viejo registra apenas un siglo y medio de presencia euroafricana. Además, la muestra de individuos coloniales excavados, ampliada con las últimas investigaciones en 2017 y 2018, con evidencia del tráfico de personas de distintas procedencias americanas y, posteriormente, africanas, documentadas en la región a lo largo de dos siglos, subraya la imposibilidad de perfilar rígidamente un único

12 Los bienes de difuntos han sido ampliamente estudiados, aunque quedan muchos expedientes por analizar. Véanse, entre otros, Vila Vilar, 1983; González Sánchez, 1995; Fernández López, 2015; Buono, 2019. Para el caso de los datos arqueológicos enunciados, véase Hernández, 2019. 13 Mendizábal, 2004. Cooke y Sánchez, 2019. 
FIGURA 1

LOCALIZACIÓN GENERAL DE PANAMÁ VIEJO Y UBICACIÓN DE LAS EXCAVACIONES EN EL CONJUNTO MONUMENTAL

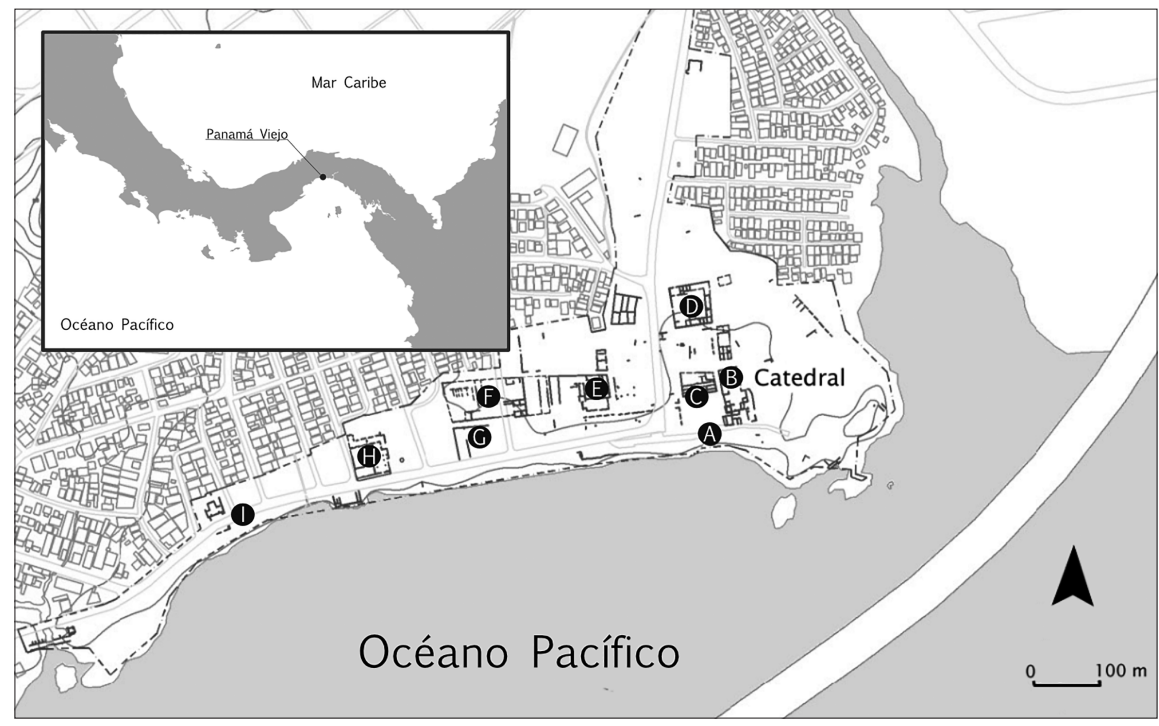

A: Sureste de la Plaza Mayor excavada en 2018, correspondiente al asentamiento inicial de la iglesia y Catedral. B: Nave y atrio en las actuales ruinas de la Catedral, excavadas en 2017, su segundo asentamiento al noreste de la Plaza Mayor a partir de 1542. C: Plaza Mayor. D: Convento de Santo Domingo. E: Convento de la Compañía de Jesús. F: Convento de la Concepción. G: Hospital de San Juan de Dios. H: Convento de San Francisco. I: Convento de la Merced.

Fuente: Elaboración de Manuela Martín.

momento de contacto - y en consecuencia de globalización — para definir un antes y un después. Aun así, es permisible valorar los efectos de los contactos iniciados a corto y mediano plazo mediante la comparación de los datos de distintos espacios funerarios.

En lugar de un «pre» y un «post» contacto, distinguidos a partir de un momento único, identificamos los inicios de un proceso irreversible, en el cual agentes americanos, europeos y africanos intervienen durante dos siglos. Se trata de un escenario en el que el impacto de la movilidad geográfica, sobre todo la forzosa, resulta cada vez más visible en las evidencias que refieren las pautas nutricionales, de salud y la longevidad. Los contextos 
funerarios prehispánicos de Panamá Viejo sugieren complejidad social, que incluye la influencia y el prestigio de ciertas mujeres que pasaron desapercibidas en las primeras relaciones castellanas. ${ }^{14}$ Esto se evidencia en, al menos, dos rasgos funerarios, arqueológicamente excavados, que presentan un conjunto de cráneos masculinos, articulados como ofrenda a individuos femeninos. El primero de ellos fue identificado en el lugar que luego ocupó la Plaza Mayor. Se trata de la tumba de una mujer, decúbito dorsal extendida, de unos 35 años de edad, que ostentaba un collar elaborado con cuentas de Spondylus spp. ${ }^{15}$ y rodeada por nueve cráneos masculinos. A un kilómetro de distancia, en dirección oeste, otra tumba de mujer presentó una ofrenda similar, que destaca la presencia de tres cráneos masculinos. ${ }^{16}$ La muestra prehispánica de unos 65 individuos, analizados por Juan Guillermo Martín, Javier Rivera y Claudia Rojas en el Patronato Panamá Viejo, ${ }^{17}$ sugirió diferenciaciones sociales dentro de la población prehispánica, que pudieron relacionarse con acceso diferencial a alimentos, la prevalencia de ciertos procesos infecciosos y el desgaste físico generado por actividades específicas asociadas a la posición social de estos individuos dentro de la comunidad. El ajuar funerario se caracteriza por la presencia de variados objetos de cerámica, roca o material orgánico, que darían cuenta de una organización social estratificada, característica que se extenderá, muy probablemente, en el contexto de la primera globalización.

Las escasas evidencias preservadas de los primeros momentos de contacto dejan ver la precariedad de las situaciones, marcadas por la insuficiente comida y las enfermedades. ${ }^{18}$ Durante sus viajes por el Mar del Sur en 1515 y 1519, Gaspar de Espinosa testificaba que a la hueste le escaseaba no solamente la salud y los alimentos, sino también el papel y la tinta para registrarlas. ${ }^{19}$ De la misma manera, las personas fallecidas en estos viajes, tanto indígenas como castellanas, se enterraban por el camino. Al mismo tiempo, los asentamientos de las primeras ciudades y villas fueron pautadas por el establecimiento de las iglesias, con la posibilidad del enterramiento

14 Andagoya, 1986 [1544]. Gaspar de Espinosa, Relaciones de sus viajes por el Mar del Sur, 1514-1516 y 1519, AGI, Patronato, 26, r. 7, n. 6 y Patronato, 294, n. 3, en Pacheco et al., 1873, 5-119 y 1882, 1-74. Sin embargo, para el caso de la «cacica» Isabel Corral, véase Díaz Ceballos, 2018.

15 De acuerdo con Cooke et al., 1998, en el istmo de Panamá este molusco se caracterizó por ser suntuario y de carácter ritual.

16 Mendizábal, 2004.

17 Martín et al., 2009. Rojas et al., 2011.

18 Mena, 2011, 215-256. Saldarriaga, 2011, 257-284.

19 Gaspar de Espinosa, Relación de su viaje por el Mar del Sur, 1514-1516, AGI, Patronato, 26, r. 7, n. 6, en Pacheco et al., 1873, 5. 
en sagrado, concretamente en el interior de los templos para las personas fallecidas en los nuevos entornos urbanos. En Panamá, específicamente, un bohío o construcción arquitectónica de tradición indígena fue consagrado en la plaza mayor como su iglesia principal con la fundación y trazado original de la ciudad en 1519. La estructura precaria y provisional, derribada por incendios y hasta un huracán, albergó las reuniones sociales y políticas más importantes de la población, normalmente tras la misa del domingo. ${ }^{20}$

El estudio de cuarenta y ocho enterramientos católicos de principios del siglo XVI, hallados al sureste de la Plaza Mayor, ha señalado la ubicación transitoria de esta primera iglesia y Catedral al lado de la línea de costa. ${ }^{21}$ La orientación de los enterramientos con los pies hacia el este, excepto en un caso — seguramente de un clérigo - ubicado en la zona del presbiterio, ${ }^{22}$ señaló asimismo la disposición canónica del templo (oeste-este). Tanto la orientación de esta primera iglesia, como sus posibles dimensiones espaciales —una superficie aproximada de $67 \mathrm{~m}^{2}$ - se pudieron inferir por el estudio y orientación de las sepulturas, así como de los artefactos relacionados con actividades religiosas católicas. Las perturbaciones posteriores en la zona próxima a la playa, tanto de época colonial —evidenciada en fragmentos de un piso de cantos rodados y un grueso muro de piedras y argamasa-, como contemporánea — fragmentos de pisos, restos de muros de cemento y cortes para instalaciones eléctricas - y la bioturbación, dejaron muy poco de la primitiva iglesia (Figura 2). ${ }^{23}$ No obstante, el análisis bioarqueológico en muchos de los casos pudo rescatar las características de algunos de los primeros pobladores europeos, así como de individuos femeninos de filiación negroide, mongoloide y mestiza.

Pese a los problemas de conservación de ambos registros, los datos arqueológicos e históricos concuerdan en la importancia del principal y único espacio funerario cristiano durante los primeros años de la ciudad. Posteriormente, otras iglesias, como la del monasterio de la Merced, fundada en 1522 y ampliada con la adición de un segundo buhío en 1526, la del

20 Reformación del repartimiento anunciado de la iglesia mayor, 9 de junio y 13 de julio de 1522, AGI, Justicia, 1042, s/f. Véase Hernández, Martín y Aram, 2020.

21 El estudio tuvo presente tanto los resultados de las excavaciones efectuadas al sureste de la Plaza Mayor en 2018 (14 individuos), como los resultados investigativos de las excavaciones ejecutadas en 2003 y 2004 en ese espacio, las que ofrecieron entonces las características bioarqueológicas de 34 individuos. Hernández, 2019.

22 La excepción a esta regla, o sea el enterramiento con los pies hacia el Este, era practicada por los propios sacerdotes, quienes eran enterrados con orientación opuesta a la feligresía. Martín y Díaz, 2000, 82.

23 Hernández, 2019. 
monasterio de San Francisco, trasladado desde Santa María del Antigua del Darién, la de Santo Domingo, construida a partir de 1566, la de la Compañía de Jesús, fundada en 1578, Nuestra Señora de la Concepción, fundada en 1594, y la iglesia de la orden de San Juan, encargada de la administración del anterior hospital de San Sebastián a partir de 1620, llegarían a competir para el enterramiento de los fieles. ${ }^{24}$

\section{FIGURA 2}

\section{ENTERRAMIENTOS HALLADOS AL SURESTE DE LA PLAZA MAYOR DE PANAMÁ VIEJO, DATADOS ENTRE 1519-154125}
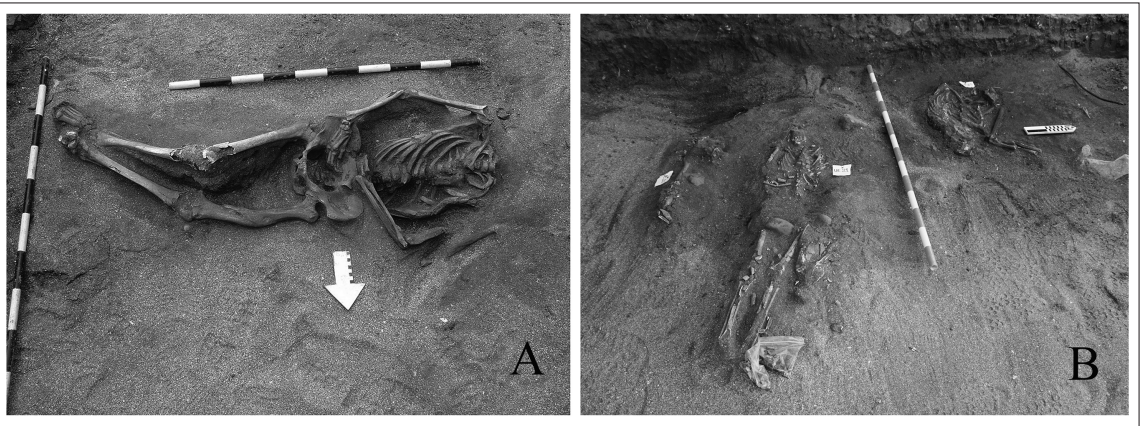

Fuente: Fotografías de Juan Martín e Iosvany Hernández.

Aunque el Archivo de Indias carece de registros de los bienes de difuntos de Panamá anteriores a 1543, conserva copias de algunas de las cuentas de los tenedores de bienes de difuntos. Estos incluyen al escribano

24 El prior de la orden de San Juan fue excomulgado por enterrar en la capilla del Hospital a Juana García, una mujer «morena libre criolla», cuyo testamento inicialmente había previsto su entierro en la Catedral, y el conflicto posteriormente se extendió a otros miembros de la orden. «Codicilo de la negra de Panamá que por haber usado del y enterrándola en el contenido descomulgaron al prior» y Sentencia de excomulgación, Panamá, 10 de marzo de 1635 y 11 de junio de 1637, AGI, Indiferente, 3076, s/f. Por la misma época, el Hospital de San Juan de Dios se resistió a entregar los cuerpos de los soldados para enterrarse en la capilla de su cofradía en el monasterio de San Francisco. El presidente de la Audiencia de Panamá al rey, Panamá, 18 de julio de 1636, AGI, Panamá, 19, r. 3, n. 38.

25 La orientación de los enterramientos permite inferir la ubicación del altar mayor. Figura 2A: Enterramiento UE-30, uno de los 34 individuos estudiados de las unidades excavadas al sureste de la Plaza Mayor en 2003 y 2004. Figura 2B: Sepulturas UE-4021, 4022 y 4023, exhumadas en la vertiente oeste de la unidad 4, excavada en 2018. Obsérvese las características del sustrato arenoso, la orientación y posición (decúbito dorsal extendido) de los cuerpos, y sus condiciones de conservación, en la mayoría de los casos perturbados por acciones constructivas en el terreno. 
Álvaro de Aguilar, nombrado tenedor de los bienes de difuntos en 1524 y fallecido el año siguiente, el alcalde Juan de Castañeda, el regidor Pascual de Andagoya, otro escribano, Cristóval Muñoz y, su albacea, el ubicuo Gonzalo Fernández de Oviedo, todos nombrados para aclarar sus cuentas. ${ }^{26}$ De esta documentación se extraen los nombres de 34 hombres fallecidos en Panamá entre 1525-1534, así como en ocasiones el valor de sus bienes (de 4 a 541 pesos) y sus oficios (marinero, carpintero, trompeta y arriero), y ciertos orígenes (Osuna, Sevilla o Portugal). ${ }^{27}$ Algunas de las deudas restadas de esos bienes incluían pagos a frailes (un tal padre Pedro Miguel), probablemente para la extremaunción o misas y, en dos casos, pagos explícitamente para «la sepultura»; de 2 pesos pagados a Antonio de Argüello por enterrar a Hernán Gómez Gallego en 1525, y de 12 pesos a Toribio de Lara, mayordomo de la iglesia, conjuntamente con el arcipreste y sacristán «por la sepultura e entierro» de Diego Farfán en 1527. Como finalmente se confirmó por cédula real en 1540, la iglesia podía cobrar los entierros de un difunto $a b$ intestado, «segund su calidad e [la] hazienda que dexare, sin que aya ponpas demasiadas» a cambio de limosnas sin «exceso ni perjuicio a los herederos forzosos», entre los que figuraba de forma eminente la Santa Cruzada. $^{28}$

Los registros del tenedor de bienes de difuntos previos a 1543 se complementan por el asiento del quinto de los bienes de difuntos intestados -58 hombres adicionales y dos mujeres- debidos a la aplicación de una bula que destinaba esta parte de sus bienes a la Santa Cruzada. ${ }^{29}$ Presumiblemente, la mayoría de estos individuos fueron enterrados en la Iglesia Mayor, aunque la nómina dista de ser completa. Las dos mujeres, Francisca de la Ciudad Real e Isabel Ruiztiza, hija de Alonso Martínez, asturiano, poseían bienes valorados en 4 y 60 pesos, respectivamente. En esta fuente documental son menos visibles los individuos de origen africano, como pudo ser Juan Portugués, mencionado sin especificaciones a su color de

26 Cédula de Carlos V a Pedrarias Dávila, gobernador, y oficiales de Castilla del Oro, 14 de marzo de 1524, AGI, Justicia, 1048, n. 2, r. 3. «Traslado de las cuentas de los bienes de difuntos de Tierra Firme», iniciado bajo Pedro de los Ríos, continuado por orden de Antonio de la Gama, gobernador, Panamá, 30 de mayo de 1530, AGI, Justicia, 1048, n. 2, r. 3.

27 Bienes de difuntos en Panamá, Panamá, 1525-1536, AGI, Justicia, 1048, n. 2, r. 3, ff. $19 \mathrm{v}-94 \mathrm{v}$.

28 La reina a don fray Tomás de Berlanga, obispo de Tierra Firme, de «nuestro consejo», 16 de febrero de 1538, AGI, Panamá, 235, 1. 6, ff. 166-167, especialmente el punto 11.

29 Los bienes de los difuntos de los muertos abintestatos, Panamá, 1535-1536, AGI, Panamá, 103 , ff. $5 v-7 v$. 
piel. ${ }^{30}$ Finalmente, la presencia indígena en los enterramientos de la iglesia primitiva, como sugieren los datos bioarqueológicos, entre ellos la morfología dental de algunos de los individuos, resulta prácticamente ausente en la documentación, salvo una referencia a «un indio y una india, esclavos» como bienes de Andrés de las Hijas, fallecido en $1534 .{ }^{31}$ Por otra parte, la llegada a Panamá de mujeres indígenas del Perú, Nicaragua, Guatemala y hasta Coxcatlán (Nueva España), frecuentemente madres de hijos de conquistadores, consta en otra documentación. ${ }^{32}$ Incluyendo o no a las personas esclavizadas, las fallecidas — - enterradas — sin bienes debían ser más numerosas que las sepulturas recuperadas en la línea de costa.

La cultura material excavada en el contexto de la primitiva iglesia subraya la utilización de los elementos relacionados con la extensión de la fe cristiana: especialmente las conchas marinas modificadas para los procesos de conversión, la mayoría en Argopecten circularis y Noetia sp., los candelabros en piedra — con forma de cáliz — y la cerámica de factura indígena con engobe de color rojo, además de doce cuentas pequeñas de un rosario de decenas, manufacturado en molusco marino y algunos alfileres utilizados en el amortajamiento de los difuntos (Figura 3). Otros artefactos hallados en las excavaciones, como una pequeña campana, llaves de candados y cerraduras, huesos de animales domésticos, mayólica panameña y sevillana, cerámica ordinaria y unas tijeras de hierro, corresponden a la ocupación posterior de este sector de la ciudad. ${ }^{33}$

La orientación del templo hacía el este marca la intencionalidad simbólica de la resurrección, lo que resulta significativo puesto que, en ocasiones, la presencia morisca y conversa en esta primera generación de pobladores transciende a la documentación, como sucedió con el legado del maestrescuela Hernando de Luque de 14 mil pesos a la Iglesia Mayor, el tercio de los provechos de la conquista del Perú, que le correspondían como inversor conjuntamente con Francisco Pizarro y Diego de Almagro. ${ }^{34}$ Asimismo, se

30 En el istmo, el apelativo o descriptor «portugués» fue común entre personas de origen o con experiencia afro-portuguesa. A la cabeza de «veinte negros», un «Juan Rodríguez Portugués» abrió el camino entre Nombre de Dios y Panamá en 1521. Interrogatorio sobre los méritos de Gaspar de Espinosa (pregunta 8), Ciudad de los Reyes (Lima), 1552, AGI, Patronato, 98A, n. 2, r. 1.

31 Bienes del difunto Andrés de las Hijas, 20 de febrero de 1534, AGI, Panamá, 234, 1. 5, ff. $134 \mathrm{v}-136$.

32 Memoriales sobre las indias llegadas a Panamá, Panamá, 1538-1539, AGI, Panamá,13, r. 1, n. 1 .

33 Hernández, 2019.

34 Bienes de Hernando de Luque a la iglesia mayor de Panamá, Panamá, 28 de septiembre de 1536, AGI, Panamá, 235, 1. 6, f. 47r-v. 
destaca la presencia póstuma de Pedro de los Ríos, gobernador de Castilla del Oro, sentenciado a financiar un retablo de la Virgen para la Iglesia Mayor, con una inscripción al pie «con letras que se pueda leer de todos como el dicho retablo se mandó hazer de cierta pena dada por haberse tratado mal [a] los indios», y con el ánimo de recalcar la obligación de cumplir con las ordenanzas para su «buen tratamiento». Las multas impuestas al gobernador incluían la fábrica de una corona de oro para otra Virgen, así como fondos para la construcción del ayuntamiento y de la nueva Catedral, a donde probablemente se trasladaría el retablo, pero no los restos mortales del gobernador. ${ }^{35}$

\section{FigURA 3}

\section{MUESTRA DE ARTEFACTOS HALLADOS EN EL NIVEL DE ENTERRAMIENTOS AL SURESTE DE LA PLAZA MAYOR EN 2018}

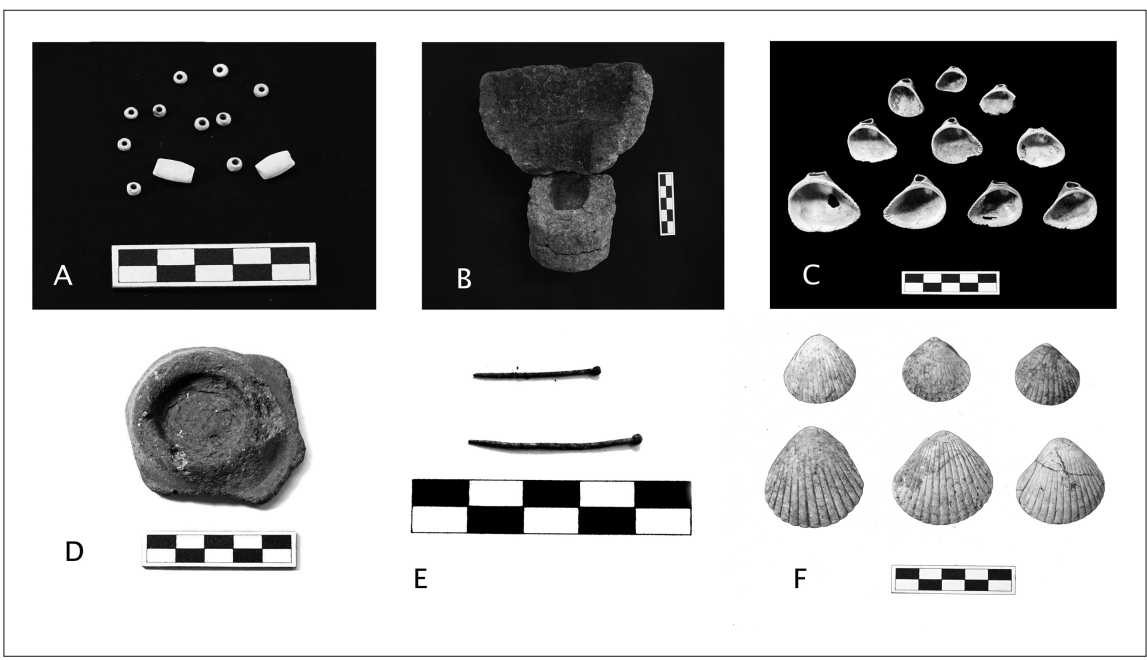

A: Cuentas de un rosario de decenas, elaboradas en molusco marino. B: Candelabro de piedra arenisca en forma de cáliz. C: Conjunto de conchas de Noetia sp., perforadas en el umbo. D: Candelabro fragmentado en la base, hecho en cerámica con engobe de color rojo. E: Alfileres de aleación de cobre. F: Conjunto de conchas de Argopecten circularis modificadas en forma ovalada al retirar las orejas al lado del umbo.

Fuente: Fotografías de Iosvany Hernández.

35 Sentencia contra Pedro de los Ríos, pronunciada por el juez de residencia licenciado de la Gama, Panamá, 6 de noviembre de 1536, AGI, Panamá, 235, 1. 6, ff. 58r-60v. 
La presencia indígena y africana entre los recientemente convertidos, conforman otras historias que, a diferencia de las de Hernando de Luque o Pedro de los Ríos, se llevaron a las tumbas, abandonadas y aparentemente olvidadas con la reubicación del templo en un promontorio rocoso al noreste de la Plaza Mayor (Figura 1). Por otra parte, tras el pago de las deudas, el entierro y la cruzada, cabe señalar la remisión de pocos bienes de difuntos a Castilla. Las necesidades del precario asentamiento prescribieron que buena parte de estos bienes fueran empleados para cumplir con la Santa Cruzada y suplir las exigencias para una buena muerte en Panamá.

\section{Reubicación y población (1542-1671)}

La construcción de una nueva Catedral de Panamá a principios de los años 1540 se proyectó con mano de obra africana e indígena acompañada por oficiales albañiles, canteros y carpinteros de la provincia de Sevilla. El nuevo emplazamiento, a unos 50 metros de la anterior, fue promovido por el obispo fray Tomás de Berlanga en 1540. Berlanga explicó que la Iglesia Mayor asentada con el trazado original de la ciudad se encontraba «en parte donde no tiene vista», y propuso su reubicación a «la delantera de la plaza donde ella tuviera vista e honrara e adornara mucho la plaza y esta ciudad». ${ }^{36} \mathrm{Al}$ parecer, la estética urbanística tomaba prioridad sobre la orientación del templo, ya que, para bordear la Plaza Mayor en su punto más alto, al este, la nueva Catedral adoptaría una orientación sur-norte, o «al revés», ${ }^{37}$ a diferencia del emplazamiento canónico de su antecesora. ${ }^{38}$ Pese a las provisiones para emprender la obra en cal y canto, terminó por imponerse la mayor disponibilidad de madera y los menores gastos que requería su construcción. ${ }^{39}$

El deseo del obispo de construir en piedra se frustró en 1541 con el naufragio de los barcos que trasportaban a Tierra Firme los tejeros, ladrilleros

36 Real cédula a los oidores de la Audiencia de Tierra Firme, Madrid, 15 de abril de 1540, AGI, Panamá, 235, 1. 7, f. 122-122v.

37 «Información fecha de oficio tocante a la iglesia de Panamá», Panamá, 6 de mayo de 1580, AGI, Panamá, 62, n. 8.

38 Las observaciones y aportaciones del historiador de la arquitectura Juan Luis Blanco han sido claves al respecto.

39 Se proyectó, igualmente, bajo la supervisión de Antón García, arquitecto de la Catedral de Santo Domingo, quien se desplazó a Panamá para este propósito. El rey a los oficiales de Tierra Firme y al obispo de Tierra Firme, fray Tomás de Berlanga, Madrid, 30 y 31 de junio de 1540, AGI, Panamá, 235, 1. 7, ff. 151-154. 
y esclavos para la empresa, incluyendo «uno de los mejores albañiles que había en Sevilla», y la pérdida de parte de su familia, conjuntamente con los libros, órganos, campanas, imágenes y ornamentos comprados para la Catedral. ${ }^{40}$ Tras el naufragio, al no poder emprenderse la obra en piedra, se construyó la iglesia de 140 pies (unos $43 \mathrm{~m}$ ) «de madera y tejas» en el punto más alto que existía en torno a la Plaza Mayor. Probablemente también esta limitación de recursos propiciaría que en ningún momento se planteara la posibilidad de trasladar a los individuos enterrados en el espacio sagrado de la primera iglesia al nuevo emplazamiento.

El interés de excavar en las ruinas visibles de la Catedral en 2017 se fundamentó en los datos de los estudios arqueológicos precedentes (años 1998 y 2000), y en la revisión de los expedientes de bienes de difuntos conservados en el Archivo General de Indias (1543-1671). En el segundo caso, se trata de 172 expedientes, algunos de los cuales incluyen testamentos, inventarios de bienes y/o almonedas (véase la Gráfica 1). Entre los 93 casos acompañados por últimas voluntades y testamentos, unos 56 contenían disposiciones concretas para el enterramiento del testador o de la testadora (en cinco casos), 31 de los cuales pedían ser sepultados en la Catedral, es decir, el $45 \%$ de los casos (véase la Gráfica 2). Estos datos son significativos, aún si se consideran representativos de una pequeña parte de la población urbana, a saber, las personas que morían en Panamá con herederos en Castilla y, por ende, no la población más pobre ni normalmente la de mayor arraigo. Entre los 31 individuos que registraron la voluntad de enterrarse en la Catedral, 18 se identificaron en relación con profesiones, oficios o estados que permitieron una primera aproximación a un abanico de situaciones sociales en las que predominan los oficios medios: un tonelero, un sastre, un carpintero «de ribera», un pulpero, un barbero, un zapatero, un alférez, cinco mercaderes (de ropa de Castilla, de plata, de sedas), dos clérigos, dos viudas y dos oidores de la Real Audiencia. ${ }^{41}$ Las disposiciones para sus enterramientos permiten un acercamiento a los distintos espacios funerarios donde la diferenciación y la pertenencia social podían influir.

40 El obispo Tomás de Berlanga al emperador, Acla, 15 de febrero de 1541, AGI, Patronato, 194, r. 60A.

41 Bienes de Juan Carrión, tonelero, Panamá, 1555, AGI, Contratación, 5576, n. 13. Bienes de Juan de la Peña, sastre, Panamá, 1565, AGI, Contratación, 471, n. 5, r. 2. Bienes de Miguel Vicente, carpintero de ribera, Panamá, 1568, AGI, Contratación, 5577, n. 31. Bienes de Andrés Navarro, mercader de ropa de Castilla, Panamá, 1577, AGI, Contratación, 214, n. 1, r. 1. Bienes de Pedro Sánchez de Requena, pulpero, Panamá, 1580, AGI, Contratación, 921, n. 10. Bienes de Pedro García de Gata, clérigo, Panamá, 1583, AGI, Contratación, 221, n. 1, r. 10. Bienes de Hernán Saco de Quiro, mercader 


\section{GRÁFICA 1}

REGISTROS DE BIENES DE DIFUNTOS EN PANAMÁ, 1543-1671

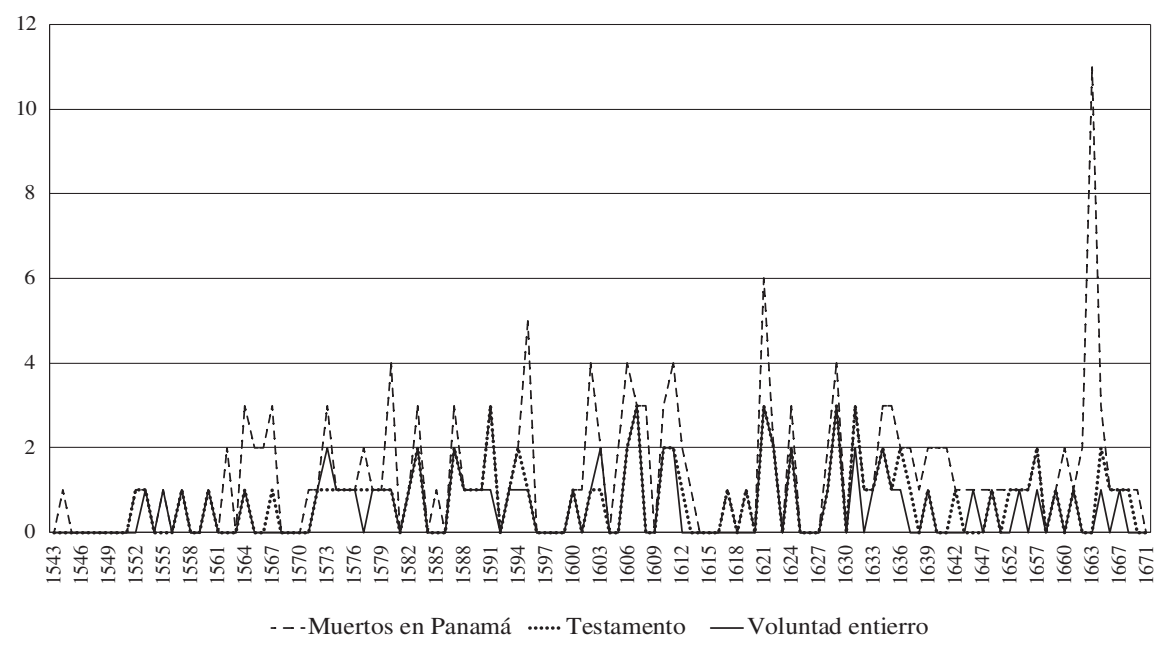

Fuente: Elaborado por Alejandro García Montón a partir de las fuentes consultadas en AGI.

La mayoría de los testadores que murieron en Panamá pedían enterrarse en la Iglesia Mayor o Catedral sin mayores precisiones, aunque casi la mitad de estas añadían «en la parte donde a mis albaceas les pareciere», una expresión que aludía a la disponibilidad de espacio o de fondos después de la venta de los bienes en almoneda o del pago de deudas y de mandas testamentarias, así como las consideraciones sociales en torno al fallecido. Existiendo o no testamento, algunas muertes claramente fueron sobrevenidas, como la de un inquisidor en tránsito hacía el Perú en compañía del

de plata, Panamá, 1584, AGI, Contratación, 223, n. 1, r. 6. Bienes de Ana de Valverde, viuda, Panamá, 1588, AGI, Contratación, 246, n. 2, r. 1, n. 4. Bienes de Juan de Góngora, barbero, Panamá, 1595, AGI, Contratación, 244, n. 24. Bienes de Juan Pérez de Villalobos, mercader, Panamá, 1627, AGI, Contratación, 955, n. 1, r. 14. Bienes del licenciado don Hernando Ibáñez de Albendea, oidor de la Real Audiencia, Panamá, 1628, AGI, Contratación, 376, n. 1, r. 5. Bienes del zapatero Matheo Sánchez Marmolejo, Panamá, 1633, AGI, Contratación, 535, n. 1, r. 2. Bienes del alférez Domingo de Lezalde y Maella, Panamá, 1634, AGI, Contratación, 960, n. 4. Bienes de Simón de Torres, mercader de sedas, Panamá, 1641, AGI, Contratación, 405, n. 12. Bienes de Felipe de Peralta Céspedes, mercader, Panamá, 1644, AGI, Contratación, 412A, n. 1, r. 8. Bienes de Francisco Martín Macotela, clérigo presbítero, Panamá, 1645, AGI, Contratación, 453A, n. 2. Bienes del doctor don Luis de la Oliva, oidor de la Real Audiencia, 1649, AGI, Contratación, 422, n. 5. Bienes de la viuda doña Clara Ortiz Montero de Castilla, Panamá, 1661, AGI, Contratación, 442B, n. 2, r. 2. 
virrey en $1569^{42}$ o la de Mateo de Coloma, originario de Toledo, quien había llegado a principios de la décimo séptima centuria a Panamá, sepultándose su cuerpo en la «iglesia más próxima a donde falleciere». ${ }^{43}$ La Catedral resultó ser el sitio más lógico para enterrar a las personas fallecidas durante su paso por la ciudad.

\section{GRÁFICA 2}

\section{LUGARES DE ENTERRAMIENTO SOLICITADOS (IGLESIAS Y MONASTERIOS) EN LOS TESTAMENTOS DE LOS DIFUNTOS EN PANAMÁ, 1543-1671}

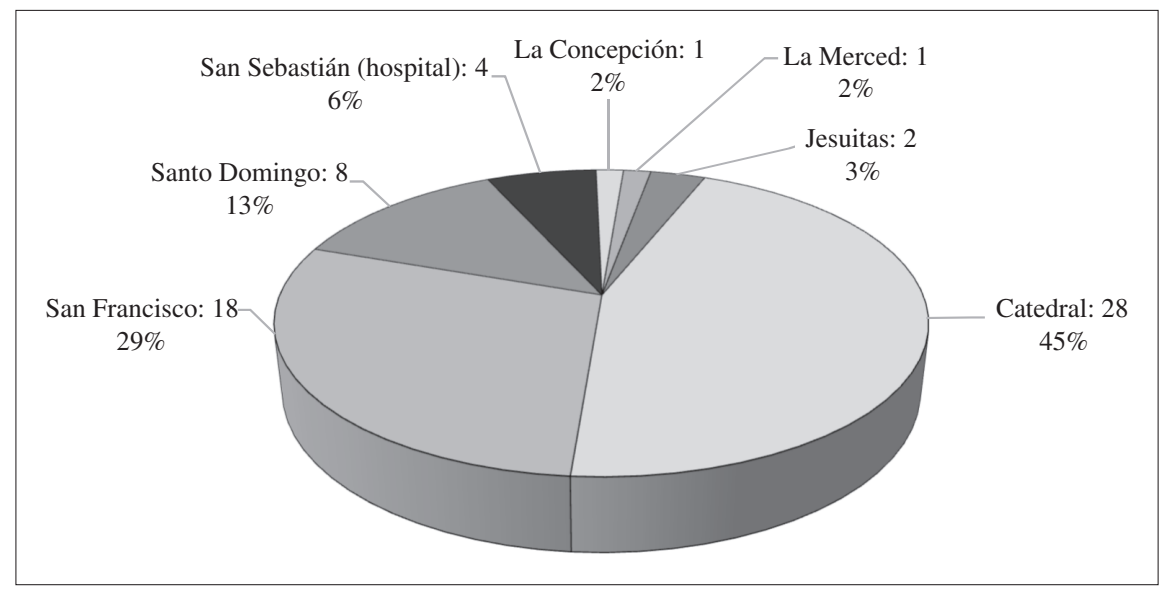

Fuente: Elaborado por Alejandro García Montón a partir de las fuentes consultadas en AGI. ${ }^{44}$

42 Extractos de cartas, Nombre de Dios y Panamá, 1569, Archivo Histórico Nacional, Madrid, Inquisición, 1. 1033, ff. 3-43.

43 Bienes de Mateo de Coloma, Panamá, 1603, AGI, Contratación, 265B, n. 4.

44 Bienes de difuntos en Panamá, Panamá, 1543-1671, AGI, Contratación, legs. 198, n. 1; 200, n. 1 , r. 10; 202A, n. 8; 205, n. 1, r. 3; 205, n. 1, r. 7; 206, n. 1, r. 14; 208B, n. 2, r. 1, n. 10; 214, n. 1, r. 1; 214 , n. 1 , r. $4 ; 217$ A, n. 2 , r. 1 , n. $5 ; 217$ B, n. 2 , r. 1 , n. $13 ; 217$ B, n. 2 , r. 1 , n. $15 ; 217$ B, n. 2 , r. 2 , n. 3 ; 221 , n. 1 , r. $10 ; 223$, n. 1 , r. $3 ; 223$, n. 1 , r. $6 ; 230$, n. 1 , r. $4 ; 232$, n. 1 , r. $3 ; 237$, n. 1 , r. $15 ; 238$, n. 4, r. 3 ; 239 , n. 1 , r. $12 ; 242$, n. 1 , r. $16 ; 244$, n. $21 ; 244$, n. $24 ; 244$, n. $3 ; 246$, n. 2 , r. 1 , n. $4 ; 252$, n. 1 , r. $6 ; 253$, n. $6 ; 254$, n. 1 , r. 1 , n. $3 ; 260$ B, n. 1 , r. $8 ; 261$, n. 7 , r. $4 ; 264$, n. 1 , r. $12 ; 264$, n. 1 , r. $14 ; 264$, n. 1 , r. 3 ; 265B, n. $4 ; 269$ B, n. 1 , r. $17 ; 271$, n. 2, r. $3 ; 279$ B, n. 1 , r. $11 ; 283$, n. 1 , r. $13 ; 283$, n. 1 , r. $21 ; 283$, n. 1 , r. $3 ; 292$, n. 1 , r. $10 ; 299$ B, n. $14 ; 299$ B, n. $16 ; 300$, n. $2 ; 303$, n. $9 ; 306$, n. 15; 307, n. 1, r. 6; 312B, n. 20; 322 , n. 1 , r. $12 ; 337$ A, n. $1 ; 338$, n. 1, r. 7; 339B, n. 1, r. 19; 345A, n. 5; 356, n. 7; 359, n. 2; 359, n. 9; 360 , n. 3 , r. $12 ; 376$, n. 1 , r. $5 ; 381$ B, n. 1 , r. 20; 383B, n. 7; 383B, n. 9; 386A, n. 1 , r. 5; 392, n. 7; 393, n. $13 ; 393$, n. $14 ; 398$ B, n. 1 , r. $17 ; 400$, n. 1 , r. $10 ; 403$, n. 1 , r. $4 ; 405$, n. $5 ; 405$, n. $12 ; 407$ B, n. 1 , r. 11 ; 412 , n. 2 , r. $2 ; 412$ A, n. 1 , r. $4 ; 412$ A, n. 1 , r. $8 ; 412$ B, n. 2 , r. $5 ; 422$, n. 4 , r. 7 ; 422, n. $5 ; 429$, n. 2 , r. 5 ; 433 , n. $6 ; 437$, n. 3 , r. $8 ; 442$ B, n. 2 , r. $2 ; 444$ B, n. 4, r. 4; 450A, n. 6, r. 2; 452, n. 1, r. 2; 452, n. 1, r. 3; 452 , n. 1 , r. $12 ; 453$ A, n. $2 ; 468$, n. 4 , r. $9 ; 471$, n. 2 , r. $2 ; 471$, n. 4 , r. $1 ; 471$, n. 5 , r. 2 , n. $1 ; 471$, n. 5 , 
Pese a la naturaleza transitoria de gran parte de la población fallecida en Panamá, algunas disposiciones testamentarias reflejan casos de un grado de arraigo tanto familiar como de asociación: en 1557, Melchor Díaz pedía que sus restos mortales se depositasen «en la misma sepultura que su mujer e hijo» ${ }^{45}$ y, en 1622 , Juan López quiso que los suyos se inhumasen «junto al púlpito, donde está enterrado mi tío y primo». ${ }^{46}$ Otros testadores quisieron hacer valer derechos derivados de sus devociones o pertenencia a cofradías: en 1606, Juan Ortega, originario de Córdoba, pidió yacer «junto al altar de Nuestra Señora de las Cruces» ${ }^{47}$, y Francisco Martín Macotella, al fallecer en 1645, había dejado claro que sus restos debían depositarse en la capilla de las Ánimas del Purgatorio, al ser «uno de los 24 de dicha cofradía», ${ }^{48}$ con la intención de que su último tránsito hacia el más allá pudiese avalarse con los beneficios de los privilegios alcanzados y las misas encargadas por esa asociación.

Cuatro de los 31 expedientes estudiados, equivalentes al $13 \%$, solicitaban el enterramiento del testador bajo la pila de agua bendita de la puerta principal de la Iglesia Mayor: Diego Sánchez, originario de la villa de Lepe, en 1580 , «debaxo de la pila de agua bendita de la puerta principal» ${ }^{49}$; tres años después, el clérigo Pedro García de Gata, nacido en Jerez de los Caballeros, «junto a la pila del agua bendita que está en la puerta principal de la dicha santa iglesia»;50 Alonso Hernández Talamino, originario de Panamá, «en la parte que pareciese a mis albaceas [...] junto a la pila del agua bendita» en $1603,{ }^{51}$ y Pedro Sánchez Amoraga, sobrino y heredero del arcediano Gil Amoraga, en $1626 .{ }^{52} \mathrm{El}$ interés por enterrarse en un lugar tan específico, compartido por hombres nacidos en ambos lados del Atlántico, respondía

r. 2 , n. $2 ; 471$, n. 5 , r. 2 , n. $4 ; 471$, n. 6 , r. 2 , n. $2 ; 471$, n. 6 , r. 2 , n. $5 ; 474$ A, n. 1 , r. 1 , n. $7 ; 475$, n. 1 , r. 7 ; 475 , n. 2 , r. $4 ; 480$, n. $8 ; 488$, n. 2 , r. $2 ; 491$, n. 1 , r. $19 ; 493$ B, n. $18 ; 498$ B, n. 5 , r. $2 ; 501$, n. 10; 533A, n. 1 , r. $14 ; 534$, n. $8 ; 535$, n. 1 , r. $2 ; 538$, n. $3 ; 542$, n. $6 ; 542$, n. $14 ; 552$, n. $1 ; 555$, n. 2 , r. $2 ; 556$, n. 1 , r. $2 ; 556$, n. 2 , r. $4 ; 557$, n. 4 , r. $3 ; 570$, n. $14 ; 572$, n. 1 , r. $2 ; 573$, n. 16 , r. $3 ; 669$, n. 19 , r. $3 ; 669$, n. 20 , r. $2 ; 920$, n. 2 bis; 920 , n. $3 ; 921$, n. 10; 928, n. 10; 928, n. 24; 929A, n. 5; 940A, n. 1; 941B, n. 13; 944B, n. 3 , r. $17 ; 949$, n. 1 , r. $38 ; 950$, n. $19 ; 955$, n. 1 , r. $14 ; 955$, n. 2 , r. $5 ; 956$, n. $15 ; 960$, n. $4 ; 961$, n. 4 ; 964A, n. 1, r. 4; 967A, n. 4, r. 12; 968, n. 3, r. 12; 970, n. 5, r. 5; 971, n. 4, r. 1; 971, n. 4, r. 5; 972, n. 1, r. $4 ; 973$, n. 3 , r. $9 ; 5576$, n. $13 ; 5577$, n. $31 ; 5577$, n. $32 ; 5577$, n. $66 ; 5578$, n. 18 , r. $7 ; 5579$, n. $1 ; 5581$, n. $90 ; 5582$, n. $20 ; 5582$, n. 24bis; 5709, n. 274.

45 Bienes de Melchor Díaz, Panamá, 1557, AGI, Contratación, 202A, n. 8.

46 Bienes de Juan López Muñoz, Panamá, 1636, AGI, Contratación, 386A, n. 1, r. 5.

47 Bienes de Juan de Ortega, 1606-1612, AGI, Contratación, 303, n. 9.

48 Bienes de Francisco Martín Macotela, Panamá, 1622, AGI, Contratación, 453A, n. 2.

49 Bienes de Diego Sánchez, Panamá, 1580, AGI, Contratación, 475, n. 2, r. 4.

50 Bienes de Pedro García de Gata, Panamá, 1582, AGI, Contratación, 221, n. 1, r. 10.

51 Bienes de Alonso Hernández Talamino, Panamá, 1600, AGI, Contratación, 941B, n. 13.

52 Bienes de Pedro Sánchez Amoraga, Panamá, 1626. AGI, Contratación, 532, n. 1, r. 3. 
al paso obligatorio de la comunidad por esta entrada, y así su mayor visibilidad al menor coste. En 1636 y 1639, los mercaderes Simón de Torres y Felipe de Peralta Céspedes, respectivamente, solicitaron para sus restos mortales otro lugar al parecer distintivo: enfrente de la puerta del coro y junto a ella. ${ }^{53}$ En estos casos, podía primar la ventaja de la proximidad a las misas cantadas en el coro de la Catedral, que Requejo y Salcedo, experto en el «gobierno del coro», estimaba en unas 1.800 misas rezadas anuales, más las 4.000 encargadas por la cofradía de las Ánimas. ${ }^{54}$ Nuevamente, se percibe en estas solicitudes el interés por los espacios centrales y transitados en la nave principal del templo, según las posibilidades económicas de las personas y las esperanzas de resurrección.

Atendiendo las posibles divergencias entre los últimos deseos expresados y los condicionantes materiales que afectaban a su ejecución, las excavaciones arqueológicas de 2017 se proyectaron en la zona «popular» de la nave de la Catedral, un espacio insuficientemente intervenido en el año 2000. Concretamente, se dispuso un área de excavación de $117 \mathrm{~m}^{2}$, posteriormente reducida a $29,5 \mathrm{~m}^{2}$, situada ligeramente al suroeste de la entrada principal del templo, ubicación probable de la pila de agua bendita, donde se había identificado previamente el depósito más profundo y, por ende, la posibilidad de recuperar los restos de un mayor número de individuos. Este detalle estratigráfico es importante porque el promontorio rocoso en donde se dispuso el templo aflora en el sector este y sur de la Catedral, impidiendo el recurrente uso funerario, como en la zona excavada, que presenta un relleno antrópico más profundo. El material cultural relacionado con los 151 individuos rescatados en la nave revela un mayor esplendor barroco en las últimas etapas de utilización del depósito, o enterramientos posteriores a la imposición de bases de cantería para sustentar los pilares de un nuevo techo de madera en 1626, concentrados en las unidades estratigráficas intermedias (1009, 1080 y 1149). Se trata, fundamentalmente, de elementos relacionados con el uso de vestimenta, joyas populares, la mortaja y del ámbito mágico-religioso, como las medallas votivas, las higas, un cascabel, cuentas de rosarios de diversas facturas y un crucifijo (Gráfica 3 y Figura 4). A grandes rasgos, la tendencia observada coincide con un auge progresivo de la riqueza advertida en los registros de bienes de difuntos

53 Bienes de Felipe de Peralta Céspedes, Panamá, 1639-1644, AGI, Contratación, 412A, n. 1, r. 8 y Contratación, 405 , n. 12.

54 «Relación sobre Panamá de D. Juan Requejo y Salcedo», Panamá, 13 de diciembre de 1640, BN, ms. 19245, en Serrano y Sanz, 1908, 32. 
(1543-1671), en relación igualmente con un uso más intensivo del espacio funerario a partir del siglo XVII. ${ }^{55}$ Esta situación se esclarece aún más al advertir las características de pobreza y austeridad en cuanto a elementos artefactuales de los niveles estratigráficos que cubren el periodo anterior (1542-1626), donde solo se registró una concha de bivalvo modificada y dos cuentas elaboradas en molusco marino en la unidad estratigráfica 1151 - piezas similares a las encontradas en el nivel funerario de la unidad excavada al sureste de la Plaza Mayor-, mientras los estratos más antiguos $(1175,1178$ y 1182$)$ no reportaron hallazgos.

\section{GRÁFICA 3}

\section{FRECUENCIA DE MATERIAL CULTURAL POR ÁMBITOS DE USO Y UNIDADES ESTRATIGRÁFICAS EN LA NAVE DE LA CATEDRAL}

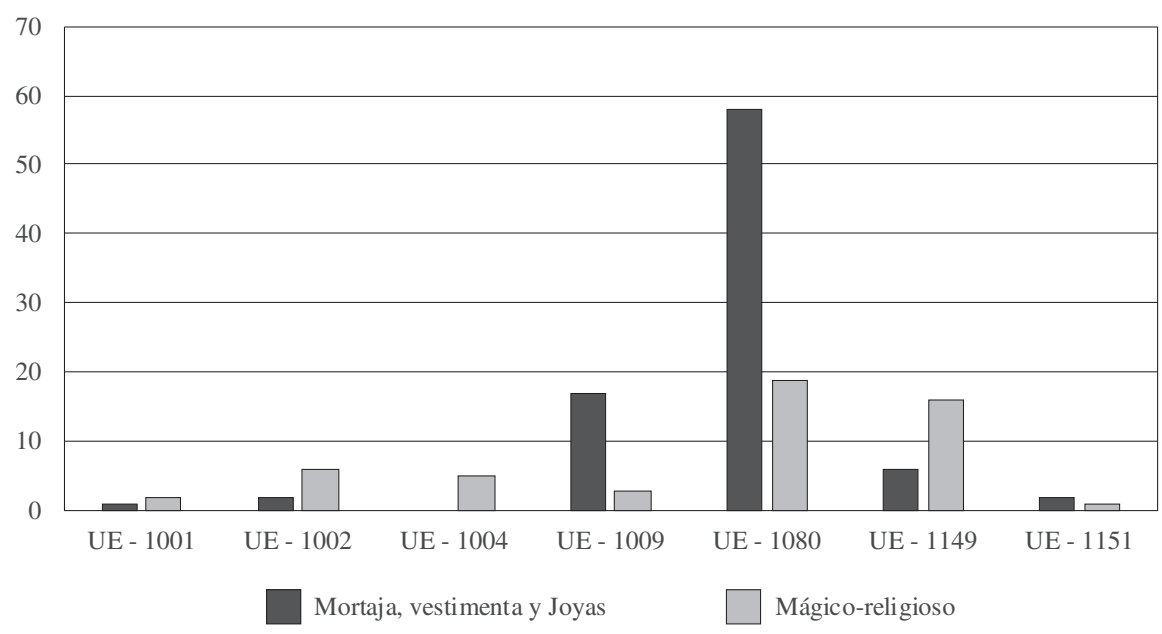

Fuente: Elaboración propia a partir de las excavaciones de 2017.

Los contrastes más significativos entre los registros arqueológicos y archivísticos conciernen al género y a las posibles filiaciones étnicas de los difuntos. En los expedientes conservados en Sevilla, solamente tres de los 31 fallecidos que expresaron el deseo de enterrarse en la Catedral de Panamá eran mujeres: una viuda, Ana de Valverde Mingolla, posiblemente mestiza,

55 Hernández, 2019. 
FIGURA 4

\section{MUESTRA DE ARTEFACTOS LOCALIZADOS EN LAS UNIDADES ESTRATIGRÁFICAS 1009, 1080 Y 1149}

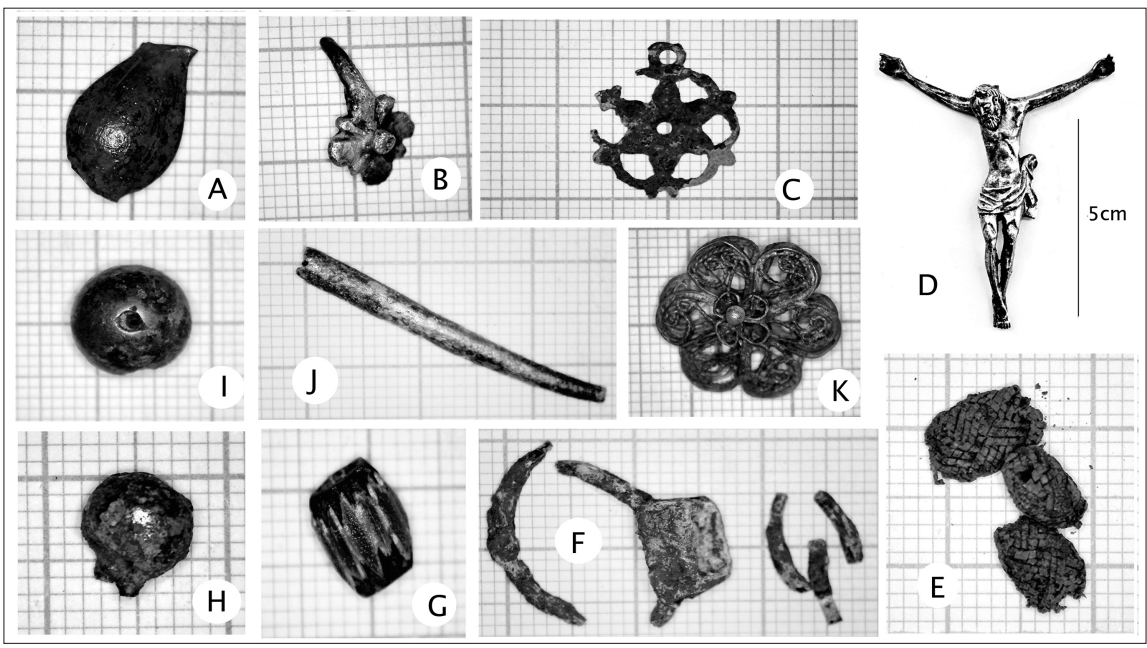

A: Colgante de un arete de vidrio traslúcido de color verde, conocido como perla Punta Rassa. B: Arete de plata en forma de flor. C: Estación de rosario en forma de estrella de seis puntas, confeccionado en aleación de cobre con dos argollas de sujeción en dos extremos, una de ellas fracturada. D: Cuerpo de Cristo moldeado en bronce con baño dorado, perteneciente a un crucifijo de madera. E: Pasamanos tejidos con hilos metálicos, utilizados en la decoración de vestimenta. F: Fragmentos de sortijas de aleación de cobre con engaste de forma cuadrada. G: Cuenta de rosario en vidrio, tipo Chevrón. H: Botón esférico de aleación de cobre con huellas de baño dorado. I: Cuenta de rosario en ámbar con huellas de tinte de color rojo. J: Herrete o agujeta metálica. $\mathrm{K}$ : Botón de plata en forma de flor en filigrana.

Fuente: Fotografías de Iosvany Hernández.

en 1588; una madre soltera, Antonia Briceño, fallecida en 1594, y otra viuda, doña Clara Ortiz Montero de Castilla, en 1661, todas dueñas de esclavas. ${ }^{56}$ Por otra parte, el análisis bioantropológico de los 151 individuos excavados en la nave en 2017 identificó a 94 mujeres o «probablemente mujeres» (el

56 Aunque Ana de Valverde Mingolla se decía «hija natural de Alonso de Valverde y de Beatriz de Valverde, naturales de Ontiveros», llama la atención la coincidencia entre el nombre de su padre, Alonso de Valverde, y el de su difunto marido (así como los de su hermano e hijo, también difunto). Testamento de Ana de Valverde Mingolla, Panamá, 30 de julio de 1588, AGI, Contratación, 246, n. 2, r. 1 (4). 
$61,45 \%)$, frente a unos 44 hombres o «probablemente hombres» (29\%) y 15 individuos $(9,15 \%)$ cuyo sexo no pudo ser precisado, según los parámetros morfológicos y antropométricos empleados en el análisis (Gráfica 4). Complementando estos datos, la valoración de los rasgos de filiación étnica, aunque indeterminados en un 42,68 \% de los casos, señaló el fenotipo negroide y mongoloide en una parte significativa de la muestra excavada, $16,56 \%$ y $5,1 \%$, respectivamente, con una representación de población probablemente caucasoide del 15,29\%. De manera igualmente significativa, se hace constar la presencia de lesiones asociadas a estrés nutricional, procesos infecciosos y enfermedades articulares, con una alta incidencia en estos individuos hasta ahora históricamente indocumentados en su mayoría. ${ }^{57}$

\section{GRÁFICA 4}

ESTIMACIÓN DE SEXO Y EDAD DE LOS INDIVIDUOS EXCAVADOS, 1543-1671

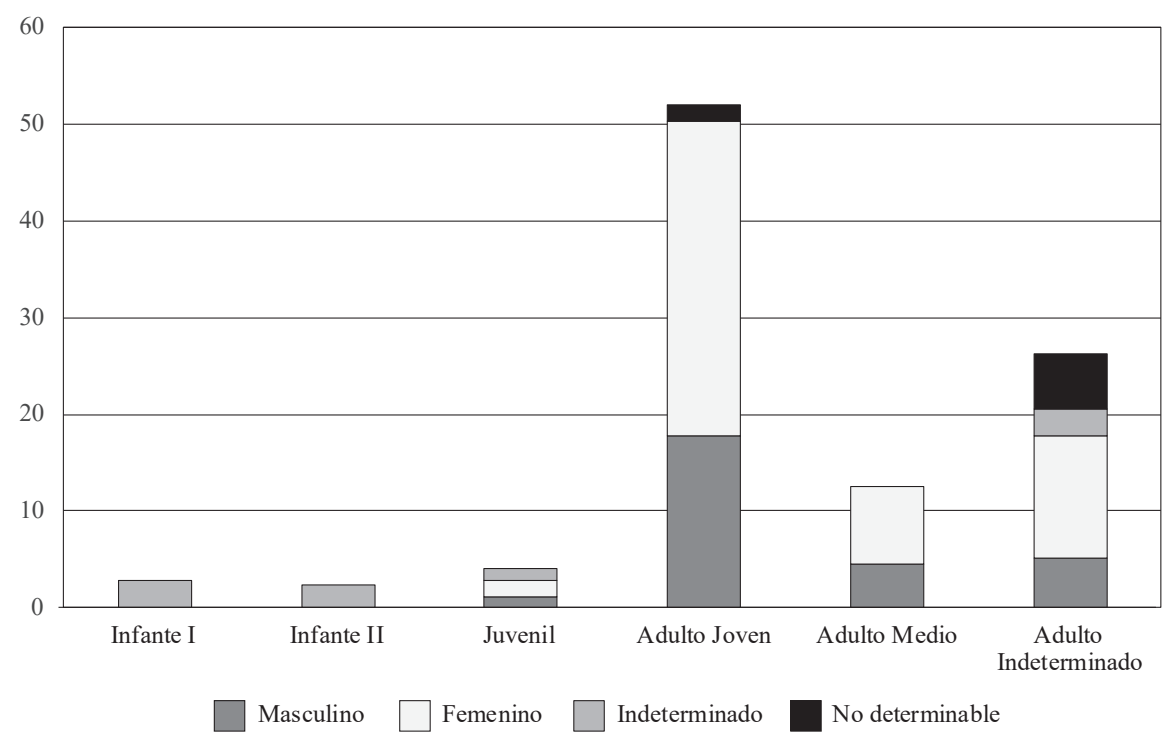

Fuente: Elaborado por Javier Rivera-Sandoval (Rivera, 2018).

Los restos mortales de muchas de las personas cuyas vidas terminaron en Panamá, fuese por vecindad, residencia, viajes, trabajos, o la situación epidemiológica y alta mortandad de la zona, acabaron en la nave de

57 Rivera, 2018. 
la Catedral. Las excavaciones arqueológicas realizadas en 2017 y 2018 demuestran la capacidad de la documentación histórica relacionada con los bienes de difuntos de reflejar solamente una pequeña parte de esta población, con poca presencia femenina y menor visibilidad africana y mestiza. El registro arqueológico, en cambio, subraya la presencia trascendental y hasta mayoritaria de una población heterogénea y femenina.

\section{Dentro y fuera de la Catedral}

Pese a sus limitaciones, los documentos históricos, desde la «Relación» del canónigo y maestrescuela Juan Requejo de Salcedo hasta los inventarios, disposiciones, testamentos y fondos enviados a la Casa de la Contratación de Sevilla, demuestran la centralidad de la Catedral para Panamá Viejo y el reino de Tierra Firme. La importancia de este espacio en la vida colonial — más allá de la presencia del obispo- se reflejó en el hecho de albergar la única pila de bautismo en toda la ciudad, y constituir, por ende, el lugar más señalado para la interacción ritual de la comunidad católica. Según Requejo, quien pudo consultar los registros, en la Catedral tendría lugar el bautismo de todos los nuevos fieles —unos 13.158 en treinta y dos años-, así como el entierro de la mayoría de los fallecidos en la ciudad, unos 8.910 «residentes, yentes y vinientes, sin los que se han muerto en el hospital e enterrándose en él, que no deben de ser pocos» entre 1613 y 1638, según los registros aún conservados en su día. ${ }^{58}$ Por consiguiente, la evidencia documental también relativiza y contextualiza el registro arqueológico.

Según los expedientes de bienes de difuntos, el costo de un entierro en la Catedral —en torno a 20 pesos, más los gastos del acompañamiento, pan, vino, cera, misas y mandas pías - no varió sustancialmente durante los dos siglos bajo consideración. ${ }^{59}$ Las cuentas para la fábrica de la iglesia en 1597 indicaron que se reunieron 761 pesos para la apertura de sepulturas en el templo, lo cual implicaría el cobro de unos 38 enterramientos en el año. ${ }^{60}$

58 «Relación sobre Panamá de D. Juan Requejo y Salcedo», Panamá, 13 de diciembre de 1640, BN, ms. 19245, f. 7v, en Serrano y Sanz, 1908, 20-21.

59 La sepultura de Antonia Briceño en la Catedral en 1598 costó unos 20 pesos, que se triplicó al sumarse los gastos de la cera, el sacristán, acompañamiento y misas, para llegar a un total de 60 pesos 3 reales. Bienes de difuntos de Antonia Briceño, Panamá, 1598, AGI, Contratación, 253, f. 48r.

60 El doctor Diego de Villanueva Zapata y el doctor Arias de Ugarte, Panamá, 20 de octubre de 1597, AGI, Panamá, 14, r. 13, n. 88. 
Por otra parte, según Requejo de Salcedo, «los funerales de todo el alto» en la Catedral podían valer unos 1.500 pesos corrientes, repartidos, al igual que las mandas pías, entre el obispo, los cinco prebendados y el sacristán. ${ }^{61}$

La Catedral no solamente fue central en la vida colonial, sino que también albergaba la posibilidad de un enterramiento en sagrado al menor coste posible. Tal fue el caso de una esclava negra con «mal de corazón» que no entendía el castellano. Tras la muerte de su dueño en Penonomé (Natá), fue llevada a Panamá, donde sufrió cámaras (problemas intestinales) y falleció en 1656. Pagados los gastos correspondientes, fue enterrada en la Catedral. ${ }^{62}$ Según el obispo en 1661, el valor de un enterramiento en la Iglesia Mayor, en el orden de los 15 pesos 6 reales, subía a un mínimo de 21 pesos para un entierro en otro monasterio, incluidos los derechos reclamados por el cabildo catedralicio. Este interés económico llevó al obispo a quejarse de una preponderancia de enterramientos de «pobres de solemnidad o esclavos negros y mulatos» en la Catedral, y la preferencia de los vecinos y extranjeros acaudalados por legar sus restos mortales a las iglesias de los monasterios que habían proliferado en la ciudad. ${ }^{63} \mathrm{Al}$ mismo tiempo, diez años antes del asedio y abandono de la ciudad, podemos considerar la posibilidad de una mayor concentración y densidad de población de origen africano, sin excluir la europea, mestiza o asiática, enterrada en la Catedral después de la legalización y reactivación del comercio negrero a partir de $1650 .{ }^{64}$

Aunque de forma escueta, los documentos históricos mencionan personas, desde miembros de la élite urbana hasta algunos esclavos «bozales» recién llegados a Panamá, que fueron enterrados fuera de la nave de la Catedral. Mientras que los acaudalados podían procurar la distinción en una capilla, incluso de otra iglesia, o mediante mayor proximidad al altar o al coro, el atrio o cementerio albergaba los restos de las personas que no se habían integrado en la comunidad de los fieles. A diferencia de la mencionada esclava de Penonomé, en 1658 los fallecidos Juan Bran y Antón de Casta Carabalí, «de la partida de negros bozales que trajeron por el Rio de

61 «Relación sobre Panamá de D. Juan Requejo y Salcedo», Panamá, 13 de diciembre de 1640, BN, ms. 19245, f. 7v, en Serrano y Sanz, 1908, 20-21.

62 «Autos sobre el cobro de los bienes de Don Alonso Román que murió en el año de 1656», Panamá, 1663-1669, AGI, Escribanía, 487B, pieza 44, f. 20v.

63 Fray Bernando de Izaguirre al Rey, Panamá, 20 de abril de 1661, AGI, Panamá, 101, n. 42.

64 García Montón, 2019. 
Chagre», fueron enterrados «fuera en el cementerio» de la Catedral.$^{65}$ Esta ubicación podría corresponder a la zona del «atrio», donde las excavaciones arqueológicas de 2017 han hallado un entierro boca abajo (Figura 5), en posición sancionatoria y dos individuos enfrentados. ${ }^{66}$ De manera que las personas enterradas en este espacio pudieron haber infligido o aún no aceptado las normas de la comunidad católica acogida en el interior de la iglesia. ${ }^{67}$ Por consiguiente, la presencia del cementerio como un área de exclusión resalta la naturaleza inclusiva e integradora de su nave, a la vez que se articula como espacio de posible salvación en la Catedral.

\section{FIGURA 5}

ENTIERRO DECÚBITO VENTRAL (UE-2008) EN LA INTERFAZ UE-2002, LOCALIZADO EN LA EXCAVACIÓN DEL ATRIO DE LA CATEDRAL EN 2017

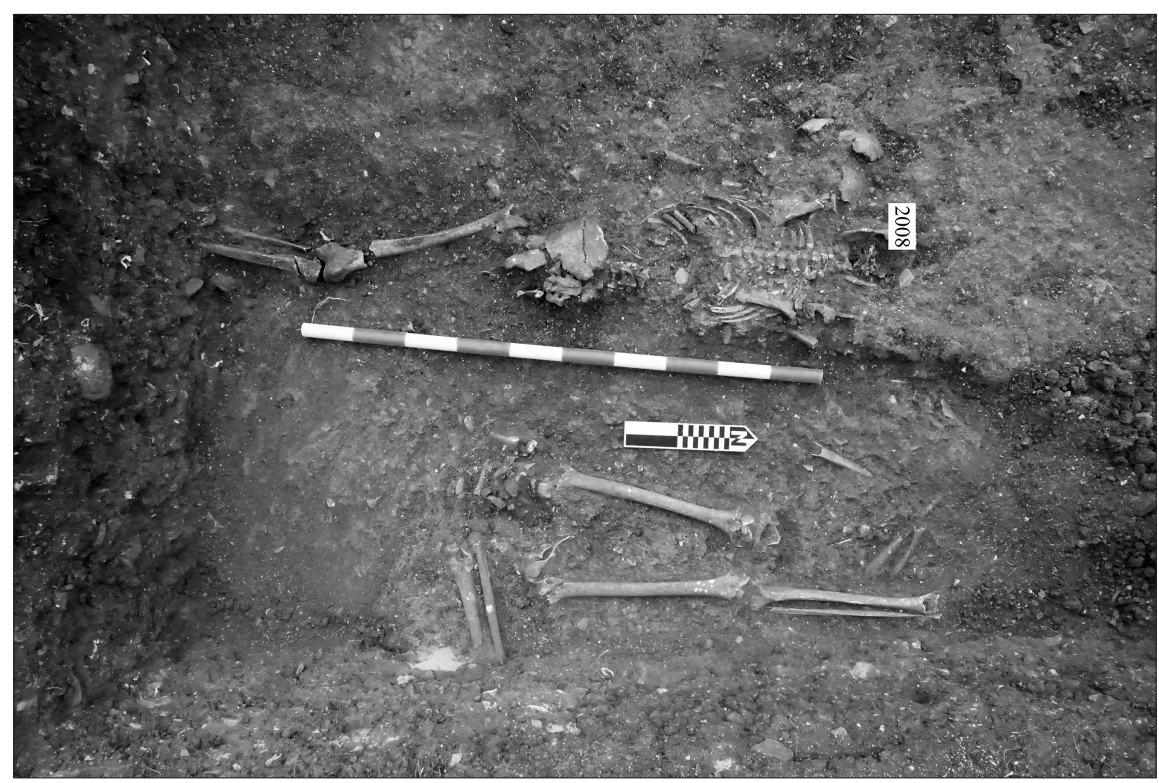

Fuente: Fotografías de Iosvany Hernández.

65 Expediente relativo a los gastos de la Audiencia de Panamá, Panamá, 1659, AGI, Panamá, 24 , r. 2 , n. 4 -i, f. 32 r- 32 v.

66 Hernández, 2019.

67 Idem. 


\section{Conclusiones}

Bajo la aparente homogeneidad y simplicidad del rito mortuorio católico, la documentación, los restos humanos y la cultura material asociada con ambos señalan la diversa procedencia geográfica y socio-económica de los individuos enterrados en la nave de la Catedral. ${ }^{68}$ Los restos humanos conservados instruyen algunos de los silencios documentales más significativos y orientan nuevas pesquisas en los archivos, más allá de los registros de bienes de difuntos, para informar las historias de los individuos muertos intestados o sin herederos en Castilla. Las implicaciones son evidentes para la historia desde abajo, así como la historia del género y de las mujeres, especialmente las africanas e indígenas que tuvieron un papel imprescindible, pero, al mismo tiempo, relativamente poco visible en la supervivencia del asentamiento. Por otra parte, las pistas documentales permiten interpretar y contextualizar los resultados de las excavaciones con mayor precisión. De la práctica arqueológica en conjunto con la histórica surgen pautas metodológicas para valorar el impacto de la movilidad geográfica, incluida la forzosa, en el ser humano, así como en su posible respuesta cultural, articulación social y movilidad socio-económica.

La documentación relacionada con los bienes de difuntos acompañaba el envío de la plata derivada de la venta en almoneda de bienes y de otras personas, algunas de cuyas vidas también acabarían en Panamá. Con mayor regularidad, los oficiales de la Casa de la Contratación en Sevilla recibían peticiones, exitosas en su mayoría, que reflejan el arte de la negociación y proyección social entre personas libres y otros agentes imperiales en el istmo. También se proyectaba tanto hacía Castilla como el Perú el reflejo de una cultura criolla con su máxima expresión en la mayólica panameña o los versos barrocos emanados de la misma ciudad. ${ }^{69}$

A la tumba se llevaba una cultura material austera y superficialmente homogénea, que respondía a las reglas funerarias de la época, que abogaban por la sencillez y la austeridad, como alfileres para fijar la mortaja, medallas religiosas y algunos rosarios. Sin embargo, aunque en pocos casos, sobresale la presencia de pasamanos y botones en alguna vestimenta, que sugieren una transgresión a las normas. En ocasiones no solo se busca

68 Aunque ya se había documentado una «integración post-mortem» entre individuos de distinta procedencia en el cementerio de la plaza mayor de Campeche, en este caso, se trata del interior de la Catedral y, por ende, un espacio de gran valor simbólico.

69 Véase Rovira y Gaitán, 2010. Serrano de Haro, 1984 [1635]. 
transportar el estatus, sino que el cadáver mismo se convierte, para los familiares y allegados, en un objeto de ostentación. ${ }^{70} \mathrm{Al}$ mismo tiempo se enterraba el testimonio del desgaste físico del intento por sobrevivir y, en algunos casos, aprovechar las posibilidades de la primera globalización, superadas solamente por sus costes.

\section{Agradecimientos}

Este artículo se basa en la investigación en curso de Javier Rivera Sandoval, Alejandro García Montón, Jorge Díaz Ceballos, Amelia Almorza Hidalgo y Tomás Mendizábal, conjuntamente con el trabajo de los autores. Se agradecen las aportaciones de todas las personas involucradas en el proyecto, así como de los miembros del seminario GRIMSE de la Universidad Pompeu Fabra, donde se presentó una versión preliminar del trabajo en 2018. Finalmente, se agradecen las recomendaciones en las evaluaciones para la aclaración y mejora del texto.

\section{Referencias bibliográficas}

Andagoya, Pascual de, Relación y documentos, edición de Adrián Blázquez, Madrid, Historia 16, 1986 [orig. 1544].

Andrén, Anders, Between Artifacts and Texts. Historical Archaeology in Global Perspective, traducción de Alan Crozier, Londres, Plenum Press, 1998.

Brandon Tuma, Nancy, «Social exchange theory», en Borgatta, Edgar y Montgomery, Rhonda (eds.), Encyclopedia of sociology, 4, New York, Macmillan

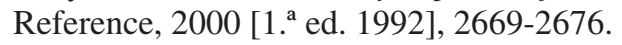

Buono, Alessandro, «"Tratándole como paysano y él a ellos”. Pertenencia local, redes supralocales y transmisión de bienes entre el Nuevo y el Viejo Mundo (siglo XVII)», Tiempos Modernos, 39, Madrid, 2019, 131-155. Disponible en: http://www.tiemposmodernos.org/tm3/index.php/tm/article/view/5361/871 [Consultado: 26/06/2020].

70 Martín, 2001/2002. 
Castillero Calvo, Alfredo, Conquista, Evangelización y Resistencia. ¿Triunfo o Fracaso de La Política Indigenista?, Panamá, Editorial Mariano Arosemena/ Instituto Nacional de Cultura, 1994.

Castillero Calvo, Alfredo, Sociedad, Economía y Cultura Material. Historia Urbana de Panamá La Vieja, Panamá, Imprenta Alloni, 2006.

Castillero Calvo, Alfredo (dir.), La Nueva Historia General de Panamá, Panamá, Comisión de 500 años, 2019, vols. I-III.

Cooke, Richard y Sánchez, Luis A., «Panamá indígena: 1501-1550», en Castillero Calvo, Alfredo (dir.), La Nueva Historia General de Panamá, Panamá, Comisión 500 Años de la Fundación, 2019, I-i, 115-160.

Cooke, Richard; Sánchez, Luis A.; Isaza, Ilean y Pérez, Aguilardo, «Rasgos mortuorios y artefactos inusitados de Cerro Juan Díaz. Una aldea precolombina del Gran Coclé», Revista La Antigua, 53, Panamá, 1998, 126-196.

Díaz Ceballos, Jorge, «New World civitas, contested jurisdictions and inter-cultural conversation in the construction of the Spanish Monarchy», Colonial Latin American Review, 27:1, Nueva York, 2018, 30-51.

Exquemelin, Alexander O., The buccaneers of América, Nueva York, Dover Publications, 1967 [1. ${ }^{\mathrm{a}}$ ed. 1678].

Fernández-López, Francisco, «El procedimiento y los expedientes de bienes de difuntos en la Casa de la Contratación de Indias (1503-1717)», Tiempos Modernos, 30, Madrid, 2015. Disponible en: http://www.tiemposmodernos.org/ tm3/index.php/tm/article/view/391/451 [Consultado: 25/06/2020].

García Montón, Alejandro, «The Rise of Portobelo and the Transformation of the Spanish American Slave Trade, 1640s-1730s: Transimperial Connections and Intra-American Shipping», Hispanic American Historical Review, 99:3, Durham, 2019, 399-249.

García Montón, Alejandro y Aram, Bethany, «La primera globalización desde América: comercio, agentes y bienes entre el mundo atlántico y pacífico, ss. XV-XVII», Nuevo Mundo. Mundos Nuevos, Paris, 8 de octubre de 2019. Disponible en: https://doi.org/10.4000/nuevomundo.77929 [Consultado: 18/06/2020].

González Sánchez, Carlos Alberto, Dineros de ventura: la varia fortuna de la emigración a Indias, Sevilla, Universidad de Sevilla, 1995.

Giner, Salvador; Lamo de Espinosa, Emilio y Torres, Cristóbal, Diccionario de Sociología, Madrid, Alianza Editorial, 2001.

Hernández Mora, Iosvany, «Materialidad de la muerte en una arteria del imperio español: la Catedral de Panamá Viejo», Tesis doctoral dirigida por Beatriz Rovira y Juan Guillermo Martín Rincón, Universidad Pablo de Olavide, Sevilla, 2019.

Hernández Mora, Iosvany; Martín, Juan Guillermo y Aram, Bethany, «The First Cathedral on America's Pacific Coast», Historical Archaeology, 54:4, Germantown (Maryland), 2020 [en prensa]. 
«Ley por la cual se regulan los conjuntos monumentales históricos de Panamá Viejo, Portobelo y el casco antiguo de la Ciudad de Panamá», Gaceta Oficial, Consejo Nacional de Legislación de la República de Panamá, 12 de enero de 1977, n. ${ }^{\circ}$ 18252, ley XCI de 22 de diciembre de 1976, 1-6.

Martín, Juan Guillermo, «Estructuras arquitectónicas, bienes muebles y adornos personales: alternativas de ostentación en la antigua ciudad de Panamá», Revista de Antropología y Arqueología, 13, Bogotá, 2001/2002, 61-72.

Martín, Juan Guillermo y Díaz, Claudia Patricia, «Enterramientos coloniales en la Catedral de Panamá La Vieja. Un ejercicio de reafirmación de las creencias religiosas», Revista Trace, 38, Ciudad de México, 2000, 80-87.

Martín, Juan Guillermo y Arango, Julieta, «Panamá Viejo: Una experiencia exitosa de gestión patrimonial», Revista de Estudios Sociales, 45, Bogotá, 2013, 158-169.

Martín, Juan Guillermo y Rovira, Beatriz, «The Panamá Viejo Archaeological Project: More than a Decade of Research and Management of Heritage Resources», Historical Archaeology, 46, Germantown (Maryland), 2012, 16-26.

Martín, Juan Guillermo; Rivera Sandoval, Javier y Rojas Sepúlveda, Claudia, «Bioarqueología. Su aporte al Proyecto Arqueológico Panamá Viejo», Canto Rodado: Revista especializada en patrimonio, 4, Panamá, 2009, 117-144.

Mena García, Carmen, La Sociedad de Panamá en el Siglo XVI, Sevilla, Diputación Provincial de Sevilla, 1984.

Mena García, Carmen, La ciudad en un cruce de caminos (Panamá y sus orígenes urbanos), Sevilla, Escuela de Estudios Hispano-Americanos, 1992.

Mena García, Carmen, «La frontera del hambre: construyendo el espacio histórico en el Darién», en Vignolo, Paolo y Becerra, Virgilio (eds.), Tierra Firme. El Darién en el imaginario de los conquistadores, Bogotá, Universidad Nacional de Colombia, 2011, 215-256.

Mendizábal, Tomás, «Panamá Viejo: An Analysis of the Construction of Archaeological Time in Eastern Panamá», Tesis doctoral, Institute of Archaeology, University College London, University of London, Londres, 2004.

Pacheco, Joaquín; Cárdenas, Francisco de y Torres de Mendoza, Luis (dirs.), Colección de Documentos Inéditos para la Historia de América y Oceanía, tomo XX [1. ${ }^{a}$ serie], Madrid, Imprenta del Hospicio, 1873.

Pacheco, Joaquín; Cárdenas, Francisco de y Torres de Mendoza, Luis (dirs.), Colección de Documentos Inéditos para la Historia de América y Oceanía, tomo XXXVII [1. a serie], Madrid, Imprenta de Manuel O. Hernández, 1882.

Ramos, Gabriela, Death and Conversion in the Andes: Lima and Cuzco, 15321670, Notre Dame, Indiana, University of Notre Dame Press, 2010.

Rivera, Javier, Análisis bioantropológico de la serie osteológica excavada en la Catedral de Panamá Viejo, temporada 2017. Informe del proyecto ERC CoG 648535, An Artery of Empire. Conquest, Commerce, Crisis, Culture and the Panamanian Junction (1513-1671), Panamá, 2018. 
Rojas Sepúlveda, Claudia; Rivera Sandoval, Javier y Martín, Juan Guillermo, «Paleoepidemiology of pre-Columbian and Colonial Panamá Viejo: a preliminary study», Bulletins et mémoires de la Société d'anthropologie de Paris, 23:1-2, París, 13 de abril de 2011, 70-82. Disponible en: https://doi.org/10.1007/ s13219-011-0033-3 [Consultado: 18/06/2020].

Rovira, Beatriz E. y Gaitán, Felipe, «Los búcaros: De las Indias para el mundo», Canto Rodado: Revista especializada en patrimonio, 4, Panamá, 2009, $39-78$.

Saldarriaga, Gregorio, «Alimentación, comunidad y poder en las fundaciones tempranas de Tierra Firme: claves para entender la mortandad de modorra en Santa María de la Antigua del Darién», Tierra Firme. El Darién en el imaginario de los conquistadores, Vignolo, Paolo y Becerra, Virgilio (eds.), Bogotá, Universidad Nacional de Colombia, 2011, 257-284.

Serrano de Haro, Antonio (ed.), Llanto de Panamá a la Muerte de Don Enrique Enríquez, Madrid, Editorial Universitaria, 1984 [1. ${ }^{\mathrm{a}}$ ed. 1642].

Serrano y Sanz, Manuel (ed.), Relaciones Históricas y Geográficas de América Central, Madrid, Librería General de Victoriano Suarez, 1908, 4-136.

Tiesler, Vera; Zabala Aguirre, Pilar; Cucina, Andrea y Kurnick, S. (eds.), Natives, Europeans, and Africans in Colonial Campeche: History and Archaeology, Gainesville, University Press of Florida, 2010.

Valcárcel Rojas, Roberto, Archaeology of Early Colonial Interaction at El Chorro de Maíta, Cuba, Gainesville, University Press of Florida, 2016.

Vila Vilar, Enriqueta, «La documentación de bienes de difuntos como fuente para la historia social hispanoamericana: Panamá a fines del siglo XVI», en Solano Pérez Lila, Francisco de Paula y del Pino Díaz, Fermín (coords.), América y la España del siglo XVI, vol. 2, Madrid, Consejo Superior de Investigaciones Científicas, 1983, 259-275.

Ward, Christopher, «Historical Writing on Colonial Panama», Hispanic American Historical Review, 69:4, Durham, 1989, 691-713.

Ward, Christopher, Imperial Panama. Commerce and Conflict in Isthmian America, 1550-1800, Alburquerque, University of New Mexico Press, 1993. 